\title{
A Comparative Study to Assess the Knowledge on Code Blue Protocol among the Nurses of General Ward and Critical Care Unit at Mahatma Gandhi Medical College and Research Institute, Puducherry, India
}

\author{
Darmanadane Nanthini ${ }^{1}$, Gunasekar Nivetha ${ }^{2}$, Subbarayan Rajeswari ${ }^{3}$
}

\begin{abstract}
Background: Code blue is generally used to indicate a patient requiring resuscitation or in need of immediate medical attention, most often as the result of a respiratory arrest or cardiac arrest. Every hospital as a part of its plans, sets a policy to determine which unit provides personnel or code blue coverage. It is very essential for every staff nurse to have an adequate knowledge regarding the code blue protocol to reduce the mortality rate especially in critical care units. A comparative study was conducted to assess the knowledge on code blue protocol between general ward and critical unit staff nurses at Mahatma Gandhi Medical College and Research Institute.

Materials and methods: Descriptive research design was used to conduct this study. Sixty nurses (30 general ward nurses and 30 critical care unit nurses) selected by purposive sampling technique, from the general ward and critical care unit includes medical ward, surgical ward, orthopaedic ward and gynaecological ward at Mahatma Gandhi Medical College and Research Institute, Puducherry. The data collected by semi structured questionnaire to assess the knowledge on code blue protocol.

Results: In critical care unit nurses, knowledge mean score is 19.30 and the standard deviation is 3.36. In general ward nurses, knowledge means the score is 15.23 and standard deviation is 2.19 . The findings show that statistically highly significant $(p \leq 0.000)$.

Conclusion:The critical care nurses are having more knowledge about code blue than general ward nurses. Code blue call is the life threatening scenario where it should be known to every nurse who was working in both critical care units and general wards.

Keywords: Cardiac arrest, Code blue, Critical care unit, General ward and staff nurses.

Pondicherry Journal of Nursing (2019): 10.5005/jp-journals-10084-12106
\end{abstract}

\section{INTRODUCTION}

In hospital area, emergency resuscitation and stabilization of medical emergency situations can be happening, ${ }^{1-5}$ that time the code blue can be used as a rapid response system. These medical emergencies require immediate attention. ${ }^{6-8}$ When a person found in cardiac or respiratory arrest (unresponsive, pulse less, or not breathing) the code blue can be started immediately. ${ }^{9-16}$

Code blue rapid response system are provided with resuscitation and stabilization immediately to established medical emergencies. ${ }^{17-18}$ The response system is in two phases. (i) Basic life support (BLS) service should be provided by hospital personnel who is the initial response. (ii) Specialized and well trained team will be the second response. ${ }^{19-23}$

Based upon the quality of standards to enable the proper establishment, the response system is being conducted with a specific response. ${ }^{24-28}$ To enable the initiation of critical BLS, all members in the hospital must be trained with BLS skills..$^{29,30}$ BLS equipment should be placed in all strategic locations within the hospital grounds where the equipment is portable or mobile to enable rapid response. ${ }^{31-34}$ Once there is a code blue, a team of doctors and paramedics (medical assistants and staff nurses), often a designated "code-team," will rush to the patient taking life-saving measures. ${ }^{35-39}$ The team uses a "crash cart," wheelchair/ stretcher, which contains important aids such as suction, oxygen, intubation equipment, ambu bag, defibrillator, resuscitation drugs
${ }^{1-3}$ Department of Child Health Nursing, Kasturba Gandhi Nursing College, Sri Balaji Vidyapeeth, Puducherry, India

Corresponding Author: Subbarayan Rajeswari, Department of Child Health Nursing, Kasturba Gandhi Nursing College, Sri Balaji Vidyapeeth, Puducherry, India, Phone: +91 9442254624, e-mail: rajeswaris@kgnc.ac.in

How to cite this article: Nanthini D, Nivetha G, Rajeswari S. A Comparative Study to Assess the Knowledge on Code Blue Protocol among the Nurses of General Ward and Critical Care Unit at Mahatma Gandhi Medical College and Research Institute, Puducherry, India. Pon J Nurs 2019;12(1):1-4.

Source of support: Nil

Conflict of interest: None

and an IV setup to stabilize the patient. ${ }^{40-44}$ The team will utilize BLS and advanced cardiac life support (ACLS) skills to resuscitate patients. $^{45-48}$

\section{Objectives}

- To assess the knowledge on code blue protocol among general ward staff nurse and critical care staff nurse.

- To compare the knowledge on code blue protocol among general ward staff nurse and critical care staff nurse.

- To find out the association between the level of knowledge on code blue protocol with selected demographic variables.

o The Author(s). 2019 Open Access This article is distributed under the terms of the Creative Commons Attribution 4.0 International License (https://creativecommons. org/licenses/by-nc/4.0/), which permits unrestricted use, distribution, and non-commercial reproduction in any medium, provided you give appropriate credit to the original author(s) and the source, provide a link to the Creative Commons license, and indicate if changes were made. The Creative Commons Public Domain Dedication waiver (http://creativecommons.org/publicdomain/zero/1.0/) applies to the data made available in this article, unless otherwise stated. 


\section{Hypotheses}

- $\mathrm{H}_{1}$-There will be difference between the level of knowledge on code blue protocol among general ward staff nurse and critical care staff nurse.

- $\mathrm{H}_{2}$-There will be an association between the levels of knowledge on code blue protocol with selected demographic variables.

\section{Materials and Methods}

Quantitative approach was used to assess the knowledge on code blue protocol among general ward nurses and critical care unit nurses at MGMCRI, Puducherry. Descriptive research design was used to conduct this study. The study was conducted in general ward and critical care unit at MGMCRI, Puducherry. The study population was general ward and critical care staff nurses at MGMCRI, Puducherry. The sample size was 60:30 general ward nurses and 30 critical care nurses. A purposive sampling technique was used. Tool used for this study was demographic variables and questionnaire to assess the knowledge on code blue protocol which includes security's first response, number of officers in code blue, depth of chest compression, techniques used to ensure understanding of orders during code blue, expansion of rapid of spontaneous circulation (ROSC), indication for defibrillation, when the monophasic defibrillator can be set, method to confirm the position of endotracheal (ET) tube, phase I consist of nurse's work during phase I, etc.

\section{Results}

\section{Major Findings}

Distribution of Demographic Variables of Staff Nurses in General Wards and Critical Care Units $(N=60)$

With regard to the age, majority of samples 15 (50\%) in critical care unit, 19 (60\%) in general ward nurses were in the age group of 26-30 years. With regard to the religion, majority of samples $23(76 \%)$ in critical care unit, $16(53 \%)$ in general ward nurses were Hindu. Regarding gender, majority of samples 20 (66\%) were males in critical care unit, $18(60 \%)$ were females in general ward nurses. Regarding experience, majority of samples 7 (24\%) were in the range of experience of 3-4 years in critical care nurses and $14(47 \%)$ were in the range of less than 2 years of experience in general ward nurses.

\section{Distribution of Knowledge of Staff Nurses in Wards and Critical Care Nurses Regarding Code Blue $(N=60)$}

Figure 1 depicts percentage distribution of knowledge of staff nurses in general wards and critical care nurses regarding code blue. In critical care area majority of samples 18 (60\%) were in the category of good; 8 (26\%) were in the category of average and $4(13 \%)$ were in the range of poor. This shows that majority of the staff in critical care were in the category of good knowledge about the code blue. In general ward areas like medical ward, surgical ward, orthopaedic ward, gynaecology ward, etc., majority of samples 15 (50\%) were in the category of poor; 9 $(30 \%)$ were in the category of average and $6(20 \%)$ were in the range of good. This shows majority of the staff in ward areas were in the category of poor knowledge about the code blue.

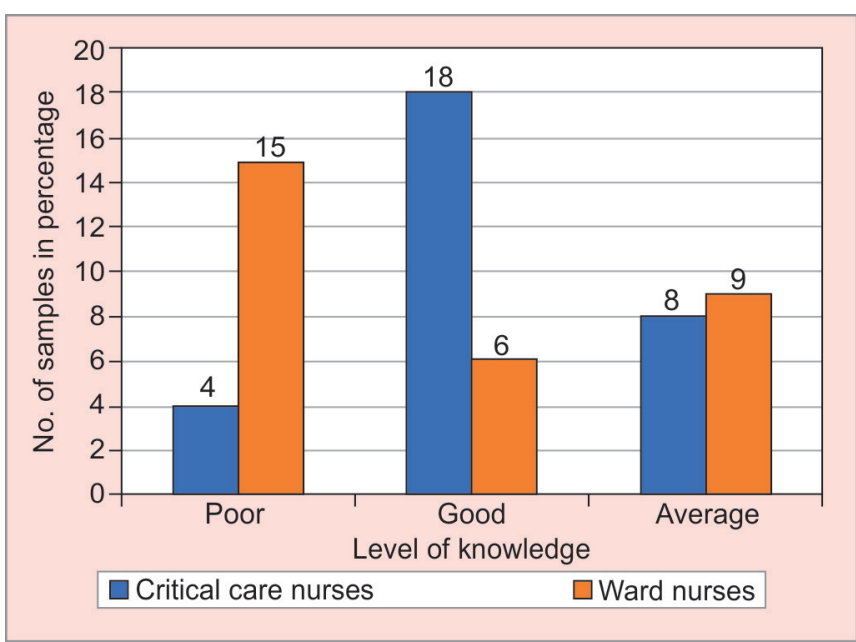

Fig. 1: Distribution of knowledge of staff nurses in wards and critical care units

Figure 2 depicts comparison of knowledge on code blue protocol among ward and critical care nurses. In critical care nurses the mean knowledge was 19.30, standard deviation was 3.36 where in general wards mean knowledge was 15.23 and standard deviation was 2.19. The calculated $p$ value $(p \leq 0.000)$ was less than 0.05 level and found statistically significant, which reveals that critical care nurses are having more knowledge about code blue than ward nurses.

Association between Levels of Knowledge of Staff Nurses with Selected Demographic Variables

There was a significant association between the level of knowledge of staff nurse with less than 2 years of experience at $p<0.038$.

\section{Conclusion}

Code blue call is the life threatening scenario ${ }^{24,25}$ where it should be known to every nurse who are working in both critical care units and general wards. The main conclusion of the study was that the general ward nurses had average knowledge and critical care nurses had good knowledge on code blue protocol.

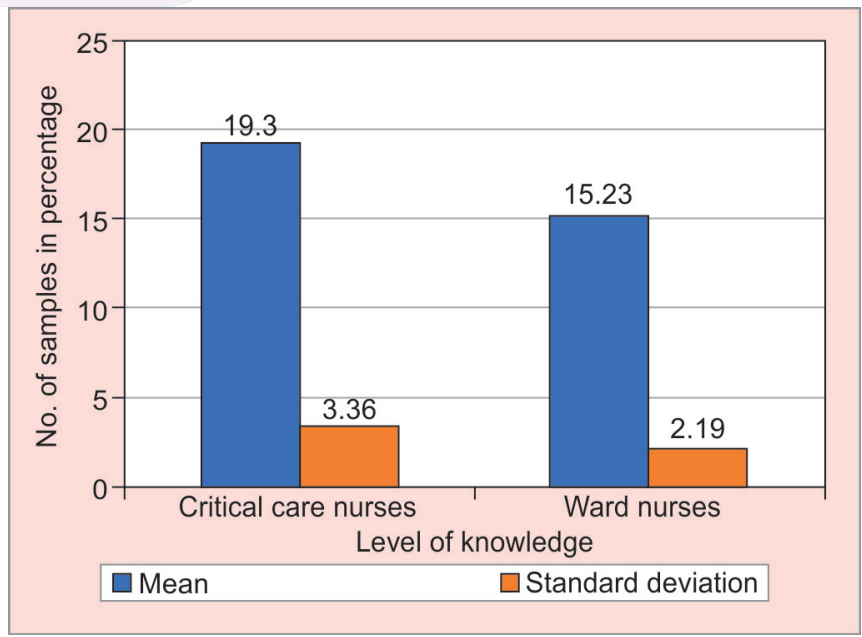

Fig. 2: Comparison of knowledge on code blue protocol among ward and critical care nurses 


\section{Decleration of Patient Consent}

The authors certify that they have obtained all appropriate patient consent forms. In the form of patient(s) has/have given his or her their consent for his/her/their images and other clinical information to be reported in the journal. Patients understand that their names and initials will be published and due efforts will be made to conceal their identity, but anonymity cannot be guaranteed.

\section{References}

1. Girotra S, Nallamothu BK, Spertus JA, Li Y, Krumholz HM, Chan PS. Trends in survival after in-hospital cardiac arrest. N Engl J Med 2012;367:1912-1920. DOI: 10.1056/NEJMoa1109148.

2. Kazaure HS, Roman SA, Sosa JA. Epidemiology and outcomes of in-hospital cardiopulmonary resuscitation in the United States, 2000-2009. Resuscitation 2013;84:1255-1260. DOI: 10.1016/ j.resuscitation.2013.02.021.

3. Peberdy MA, Ornato JP, Larkin GL, Braithwaite RS, Kashner TM, Carey SM, et al. Survival from in-hospital cardiac arrest during nights and weekends. JAMA 2008;299:785-792. DOI: 10.1001/jama.299.7.785.

4. Price JW, Applegarth O, Vu M, Price JR. Code blue emergencies: a team task analysis and educational initiative. CMEJ 2012;3:4-20.

5. Jones DA, Mitra B, Barbetti J, Choate K, Leong T, Bellomo R. Increasing the use of an existing medical emergency team in a teaching hospital. Anaesth Intensive Care 2006;34:731-735. DOI: 10.1177/0310057X0603400606.

6. Brindley PG, Markland DM, Mayers I, Kutsogiannis DJ. Predictors of survival following in-hospital adult cardiopulmonary resuscitation. CMAJ 2002;167:343-348.

7. Meaney PA, Nadkarni VM, Kern KB, Indik JH, Halperin HR, Berg RA. Rhythms and outcomes of adult in-hospital cardiac arrest. Crit Care Med 2010;38:101-108. DOI: 10.1097/CCM.0b013e3181b43282.

8. Cohn AC, Wilson WM, Yan B, Joshi SB, Heily M, Morley P, et al. Analysis of clinical outcomes following in-hospital adult cardiac arrest. Intern Med J 2004;34:398-402. DOI: 10.1111/j.14455994.2004.00566.x.

9. Larsen MP, Eisenberg MS, Cummins RO, Hallstrom AP. Predicting survival from out-of-hospital cardiac arrest: a graphic model. Ann Emerg Med 1993;22:1652-1658. DOI: 10.1016/S0196-0644(05)81302-2.

10. Ali B, Zafari AM. Narrative review: cardiopulmonary resuscitation and emergency cardiovascular care: review of the current guidelines. Ann Intern Med 2007;147:171-179. DOI: 10.7326/0003-4819-147-3200708070-00006.

11. Marsch SC, Müller C, Marquardt K, Conrad G, Tschan F, Hunziker PR. Human factors affect the quality of cardiopulmonary resuscitation in simulated cardiac arrests. Resuscitation 2004;60:51-56. DOI: 10.1016/ j.resuscitation.2003.08.004.

12. Sodhi K, Singla MK, Shrivastava A. Impact of advanced cardiac life support training program on the outcome of cardiopulmonary resuscitation in a tertiary care hospital. Indian J Crit Care Med 2011;15:209-212. DOI: 10.4103/0972-5229.92070.

13. Chan PS, Jain R, Nallmothu BK, Berg RA, Sasson C. Rapid response teams: a systematic review and Meta-analysis. Arch Intern Med 2010;170:18-26. DOI: 10.1001/archinternmed.2009.424.

14. Chan PS, Khalid A, Longmore LS, Berg RA, Kosiborod M, Spertus JA. Hospital-wide code rates and mortality before and after implementation of a rapid response team. JAMA 2008;300: 2506-2513. DOI: 10.1001/jama.2008.715.

15. Pantazopoulos I, Tsoni A, Kouskouni E, Papadimitriou L, Johnson EO, Xanthos T. Factors influencing nurses' decisions to activate medical emergency teams. J Clin Nurs 2012;21:2668-2678. DOI: 10.1111/j.13652702.2012.04080.x.

16. Shin TG, Jo IJ, Song HG, Sim MS, Song KJ. Improving survival rate of patients with in-hospital cardiac arrest: five years of experience in a single center in Korea. J Korean Med Sci 2012;27:146-152. DOI: 10.3346/jkms.2012.27.2.146.
17. Merchant RM, Berg RA, Yang L, Becker LB, Groeneveld PW, Chan PS American Heart Association's Get with the Guidelines-Resuscitation Investigators. Hospital variation in survival after in-hospital cardiac arrest. J Am Heart Assoc 2013;3:e000400. DOI: 10.1161/ JAHA.113.000400.

18. Zafari AM, Zarter SK, Heggen V, Wilson P, Taylor RA, Reddy K. A program encouraging early defibrillation results in improved in-hospital resuscitation efficacy. J Am Coll Cardiol 2004;44:846-852. DOI: 10.1016/j.jacc.2004.04.054.

19. Al-Aboud KM, Al-Aboud DM. Hospital emergency codes. An appraisal. Saudi Med J 2010;31:1377.

20. Han JE, Trammell AR, Finklea JD, Udoji TN, Dressler DD, Honig EG, et al. Evaluating simulation-based ACLS education on patient outcomes: a randomized, controlled pilot study. J Grad Med Educ 2014;6:501-506. DOI: 10.4300/JGME-D-13-00420.1.

21. Lanciano T, Curci A, Semin GR. The emotional and reconstructive determinants of emotional memories: an experimental approach to flashbulb memory investigation. Memory $2010 \mathrm{Jul} ; 18(5): 473-485$. DOI: 10.1080/09658211003762076.

22. Barbetti J, Lee G. Medical emergency team: a review of the literature. Nurs Crit Care 2008;13:80-85. DOI: 10.1111/j.1478-5153.2007. 00258.x.

23. Cummins RO, Ornato JP, Thies WH, Pepe PE. Improving survival from sudden cardiac arrest: the "chain of survival" concept. A statement for health professionals from the Advanced Cardiac Life Support Subcommittee and the Emergency Cardiac Care Committee, American Heart Association. Circulation 1991;83:1832-1847. DOI: 10.1161/01.CIR.83.5.1832.

24. Sandroni C, Nolan J, Cavallaro F, Antonelli M. In-hospital cardiac arrest: Incidence, prognosis and possible measures to improve survival. Intensive Care Med 2007;33:237-245. DOI: 10.1007/s00134006-0326-z.

25. Tee A, Calzavacca P, Licari E, Goldsmith D, Bellomo R. Bench-tobedside review: the MET syndrome-the challenges of researching and teams. Crit Care 2008;12:205. DOI: 10.1186/cc6199.

26. Hunt EA, Walker AR, Shaffner DH, Miller MR, Pronovost PJ. Simulation of in-hospital pediatric medical emergencies and cardiopulmonary arrests: highlighting the importance of the first 5 minutes. Pediatrics 2008;121:e34-e43. DOI: 10.1542/peds.2007-0029.

27. Skrifvars $M B$, Rosenberg $P H$, Finne $P$, Halonen $S$, Hautamäki $R$, Kuosa $\mathrm{R}$, et al. Evaluation of the in-hospital utstein template in cardiopulmonary resuscitation in secondary hospitals. Resuscitation 2003;56:275-282. DOI: 10.1016/S0300-9572(02)00373-8.

28. Paniagua D, Lopez-Jimenez F, Londoño JC, Mangione CM, Fleischmann K, Lamas GA. Outcome and cost-effectiveness of cardiopulmonary resuscitation after in-hospital cardiac arrest in octogenarians. Cardiology 2002;97:6-11. DOI: 10.1159/000047412.

29. Abe T, Tokuda Y, Ishimatsu S. Predictors for good cerebral performance among adult survivors of out-of-hospital cardiac arrest. Resuscitation 2009;80:431-436. DOI: 10.1016/j.resuscitation.2008.12.010.

30. Bolandparvaz SH, Mohammadzadeh A, Amini A, Abbasil HR, Ahmadi MM, Ghaffaripour S. Cardiopulmonary arrest outcome in Nemazee hospital, Southern Iran. IRCMJ 2009;11:437-441.

31. Spearpoint KG, Gruber PC, Brett SJ. Impact of the immediate life support course on the incidence and outcome of in-hospital cardiac arrest calls: An observational study over 6 years. Resuscitation 2009;80:638-643. DOI: 10.1016/j.resuscitation.2009.03.002.

32. Denzin NK. The research act in sociology. London: Butterworths; 1970.

33. Garcia-Hejl C, Chianéa D, Dedome E, Sanmartin N, Bugier S, Linard $C$, et al. Internal audit in medical laboratory: What means of control for an effective audit process? Ann Biol Clin (Paris) 2013;71: 615-624.

34. Ebell MH, Becker LA, Barry HC, Hagen M. Survival after in-hospital cardiopulmonary resuscitation. A meta-analysis. J Gen Intern Med 1998;13:805-808. DOI: 10.1046/j.1525-1497.1998.00244.x.

35. Rea T, Olsufka M, Yin L, Maynard C, Cobb L. The relationship between chest compression fraction and outcome from ventricular fibrillation 
arrests in prolongedresuscitations. Resuscitation 2014;85:879. DOI: 10.1016/j.resuscitation.2014.02.026.

36. Mondrup F, Brabrand M, Folkestad L, Oxlund J, Wiborg KR, Sand NP, Knudsen T. In-hospital resuscitation evaluated by in situ simulation: a prospective simulation study. Scand J 2011;19:55. DOI: 10.1186/17577241-19-55.

37. Yeung JH, Ong GJ, Davies RP, Gao F, Perkins GD. Factors affecting team leadership skills and their relationship with quality of cardiopulmonary resuscitation. Crit Med 2012;40:2617-2621. DOI: 10.1097/CCM.0b013e3182591fda.

38. Nadkarni VM, Larkin GL, Peberdy MA, Carey SM, Kaye W, Mancini ME, et al. First documented rhythm and clinical outcome from in-hospital cardiac arrest among children and adults. JAMA 2006;295:50-57. DOI: 10.1001/jama.295.1.50.

39. Saghafinia $M$, Motamedi $M H$, Piryaie $M$, Rafati $H$, Saghafi $A$, Jalali $A$, et al. Survival after in-hospital cardiopulmonary resuscitation in a major referral center. Saudi J Anaesth 2010;4:68-71. DOI: 10.4103/1658-354X.65131.

40. Sandroni C, Ferro G, Santangelo S, Tortora F, Mistura L, Cavallaro F, et al. In-hospital cardiac arrest: survival depends mainly on the effectiveness of the emergency response. Resuscitation 2004;62: 291-297. DOI: 10.1016/j.resuscitation.2004.03.020.

41. Merriam SB. Qualitative research. Wiley; 2014.

42. Smith KK, Gilcreast D, Pierce K. Evaluation of staff's retention of ACLS and BLS skills. Resuscitation 2008;78:59-65. DOI: 10.1016/ j.resuscitation.2008.02.007.
43. Peberdy MA, Kaye W, Ornato JP, Larkin GL, Nadkarni V, Mancini ME, et al. Cardiopulmonary resuscitation of adults in the hospital: a report of 14720 cardiac arrests from the national registry of cardiopulmonary resuscitation. Resuscitation 2003;58:297-308. DOI: 10.1016/S0300-9572(03)00215-6.

44. Davis DP, Graham PG, Husa RD, Lawrence B, Minokadeh A, Altieri $\mathrm{K}$, et al. A performance improvement-based resuscitation programme reduces arrest incidence and increases survival from in-hospital cardiac arrest. Resuscitation 2015;92:63-69. DOI: 10.1016/ j.resuscitation.2015.04.008.

45. Fung L, Boet S, Bould MD, Qosa H, Perrier L, Tricco A, et al. Impact of crisis resource management simulation-based training for interprofessional and interdisciplinary teams: a systematic review. J Interprof Care 2015;29:433-444. DOI: 10.3109/13561820.2015. 1017555.

46. Boet S, Bould MD, Fung L, Qosa H, Perrier L, Tavares W, et al. Transfer of learning and patient outcome in simulated crisis resource management: a systematic review. Can J Anaesth 2014;61:571-582. DOI: 10.1007/s12630-014-0143-8.

47. Rafati H, Saghafi A, Saghafinia M, Panahi F, Hoseinpour M. Survival after in-hospital cardiopulmonary resuscitation in a major referral center during 2001-2008. Iran J Med Sci 2011;36:50-53.

48. Herlitz J, Rundqvist S, Bång A, Aune S, Lundström G, Ekström L, et al. Is there a difference between women and men in characteristics and outcome after in hospital cardiac arrest? Resuscitation 2001;49:15-23. DOI: 10.1016/S0300-9572(00)00342-7. 